\title{
Integration of hands-on laboratory modules to enhance the introduction of ocean science and engineering to undergraduates
}

\author{
A. H. Techet, T. T. Truscott, M. K. Thompson \\ Massachusetts Institute of Technology \\ 77 Massachusetts Avenue; Cambridge, MA 02139 USA \\ Email: \{ahtechet, truscott, mkt\}@mit.edu
}

\begin{abstract}
Ocean science and engineering are exciting and active fields industry as well as academia. "Revolutionizing" marine science and technology requires that future generations have access to strong academic programs in ocean science and engineering. Undergraduates pursing degree programs in ocean engineering at the Massachusetts Institute of Technology (MIT) are introduced to a wide range of engineering topics that are highly relevant in modern ocean research, exploration and utilization. A new degree program in Mechanical and Ocean Engineering, introduced recently, strives to educate students in the engineering fundamentals required for developing new technologies to operate in the complex ocean environment. Presented here is a framework for introducing the topic of Ocean Science and Engineering (OSE) to first year students to enable three major events: (1) to draw more undergraduate students into the field of Ocean Engineering and to the new Bachelors of Science degree program in Mechanical and Ocean Engineering at MIT, (2) to create a context in which students relate material that they learn in their core program subjects back to the ocean, and thus increase their retention of this knowledge, and (3) to generate life-long interest in ocean science and engineering.
\end{abstract}

This paper discusses several innovative hands-on teaching modules that were developed for a one-term subject geared towards first and second year college students. This project-based approach aims to develop fundamental ocean instruments used in ocean exploration, while addressing the engineering challenges of working such a demanding environment. This subject material can also serve as an introduction to engineering in general.

\section{INTRODUCTION}

Ocean science and engineering is a highly multi-disciplinary field, drawing scientists and engineers together in pursuit of a more comprehensive understanding of our ocean environment. Teams working on developing technologies and systems for ocean-going vessels or for research platforms and instrumentation, are often comprised of engineers with varied backgrounds (e.g. electrical engineering, optical engineering, mechanical engineering, ocean engineering, etc.). The recent shift towards developing instrumentation and networks for ocean observatories requires even further cross-disciplinary collaborations bringing chemists, biologists, geologists, physical oceanographers, together with engineers to ultimately create cohesive sensor networks and monitoring systems in the ocean. Students emerging from degree programs in ocean engineering must be prepared for working in such multidisciplinary teams on large complex systems projects.

Historically, it has been challenging to draw students into Ocean Engineering who were not previously aware of or interested in the field (see discussion in [1]). However, many students become engaged in this field through exposure to undergraduate research projects in ocean engineering or various student activities, such as the ROV team which competes in the Marine Advanced Technology Education (MATE) ROV competition each year. Following the merger between the Departments of Ocean Engineering and Mechanical Engineering at the Massachusetts Institute of Technology (MIT), a new undergraduate degree program emerged, combining the fundamental principles of mechanical engineering with core aspects of ocean science and engineering. This degree, approved by the MIT faculty, offers students a Bachelors of Science degree in Mechanical and Ocean Engineering.

This new degree program builds on the strong tradition of Ocean and Mechanical Engineering education at MIT. In the early 1990's, MIT's Department of Ocean Engineering shifted from a Naval Architecure and Marine Engineering focus towards a broader definition of Ocean Engineering with an emphasis on complex marine systems and the marine environment in which these systems operate [1].

Today we still face challenges in attracting students to Ocean Engineering degree programs, thus reinforcing the need for an introductory level class that excites students and reveals the myriad of career and research opportunities in ocean engineering. This class can also serve as an excellent introduction to engineering to students in any field. By developing a project-based engineering subject focused on the oceans and ocean-going technologies which is designed for first and second year students, we hope to increase the awareness among younger students of the ocean and ocean engineering, and ultimately increase enrollment in the new degree program. 
This class surveys the history, the future and the critical importance of the ocean in global climate change and in our daily lives, and ideally creates a framework in which students can relate material that they learn in subsequent math and engineering subjects back to the ocean and to ocean engineering. This course offers students provides first year students, who have only studied the basic sciences (biology, chemistry and physics) and mathematics (calculus) subjects, with an introduction to fundamental engineering concepts, tools and skills that will be useful in almost any degree program at MIT.

Inductive teaching (or learning) methods, such as project-based learning, have been shown to significantly improve students' overall understanding of engineering subject materials and to increase excitement about engineering at the undergraduate level. [2] presents an excellent introduction to, and review of, the benefits of several inductive learning and teaching techniques. Generally shown to be more effective than the traditional lecture or "chalk-talk", these inductive methods establish the need to know, i.e. the why, and present specific data, case studies, or complex real-world problems instead of just presenting or deriving the theories [2]. Students then start to realize that they need more information: facts, rules, theorems, or tools. From here instructors can present them with the requisite knowledge or help students to figure it out for themselves. Ideally these methods can create more enlightened and self-motivated students capable of quickly learning new concepts and adapting these concepts to complex problems which they encounter in future subjects, in their thesis research or in their careers.

Often in project-based learning environments, collaborative or cooperative learning is done through groups and teams both in and out of the classroom. This type of experience is especially beneficial for undergraduates in ocean engineering, as the complex systems used in our field are typically designed, built and operated by teams of technicians, researchers and scientists. While the major team/group experience comes in the Junior and Senior year capstone design sequence in the MIT Mechanical and Ocean Engineering degree program, such an introductory course is a valuable teaching tool to younger students who may have never experienced such classes before. This can also set the students up for a more successful capstone experience.

The project modules discussed herein include an extension of the highly successful MIT SeaGrant SeaPerch Program, developed by Dr. Thomas Consi and Prof. Chrys Chryssostomidis, developed for K-12 and pre-college programs [3]. The core module for this class is centered on the construction of a basic remotely operated vehicle (ROV) outfitted with simple ocean sampling instruments (temperature, pressure, video, basic navigation, water sampling, and acoustics transducers). The students are immersed in the design and construction aspect of this project at the outset of the subject.

\section{Project MOdules FOR InTROdUCtion to OSE}

While developing this course, and after in-depth discussions with many undergraduate students in ocean engineering, several key reflections were taken under consideration: (1) many first year students have had no prior exposure to engineering (and many do not really know what an engineer does) and (2) many undergraduates have never heard of ocean engineering before coming to MIT. MIT students, in my experience, however, are highly curious and enjoy being challenged intellectually in the classroom. In teaching Introduction to Ocean Science and Engineering (OSE) for the first time, we combined both traditional teaching methods with more active, inductive teaching/learning approaches.

Several project-modules, focused around the design and construction of a Remotely Operated Vehicle (ROV), were introduced to give the students experience with fundamental engineering tools and skills that would be useful in most engineering disciplines. Initial introductory modules grew into a larger group project focused on integrating various instruments onto a basic ROV frame.

The project modules were developed with six distinct outcomes assessed to evaluate the effectiveness of the modules:

Outcome 1: Improved student achievement of subject learning objectives related to both ocean science and ocean engineering.

Outcome 2: Increased understanding of the fundamental challenges associated with operating in the marine environment. including ocean properties, sound propagation in the ocean and basic hydrostatics and stability.

Outcome 3: Improved communication and group learning skills in student-student and student-faculty contexts.

Outcome 4: Increased student satisfaction and interest in ocean science and engineering.

Outcome 5: Increased enrollment in subject by sophomores outside mechanical engineering, including advanced first year students, as a result of interactive education environment and introduction to engineering through project based learning.

Outcome 6: Continued interest in and study of ocean science and engineering beyond this subject, throughout the student's undergraduate studies and into their future career.

Instrumentation projects included the development and construction of classical sensors used in ocean science and engineering (eg. pressure and temperature), a computerized vehicle control system, and integration of all instruments through a LabView student data acquisition system. The hands-on curriculum also incorporated training modules in basic tool skills, such as how to solder or use a multi-meter or oscilloscope, and how to use basic shop and hand tools, such as the drill press and band-saw. Taking the time to teach students a few fundamental skills initially often gave the students just enough confidence to tackle a project or problem that was 
completely foreign. Teaching of these skills was done through the construction of a basic PVC framed ROV (figure 1 top), motors and basic motor control box.

This first class of students ranged in skill and year; $50 \%$ of the class were sophomores, 30\% freshmen and $20 \%$ juniors from other departments (chemical engineering and electrical engineering). There were 10 undergraduate students in the subject, one instructor, one full teaching assistant and one graduate student taking the class for the introduction to ocean engineering. As a side note, though not the focus of this paper, the class enrollment was $60 \%$ women.

\section{A. Basic Vehicle Construction and Engineering Tools}

The ROV, named MegaPerch by the students, was constructed following the spirit of the MIT Advanced SeaPerch (see [3] for a detailed, on-line guide to the SeaPerch programs) out of $1 / 2$ " Schedule 40 PVC pipe. The students were expected to design their own frame based on several brainstorming sessions centered on the types of instrumentation and hardware that might need to be mounted to the frame. This initial brainstorming session required significant leadership from the Teaching Assistant as the students were not quite comfortable with the group environment yet.

Following the brainstorming session and a brief safety lecture, the students started cutting the PVC and assembling the frame. A few parts required cutting using machine tools and these techniques were taught by the TA or instructor on an as needed basis. This on-the-spot teaching was done typically in small groups which helped students become more familiar and comfortable with the equipment than if it had been shown to them in a large group.

Basic electronics and soldering was taught to the students in the context of making the diode light banks, motors and motor controller for the ROV. A thorough handout, or "How To" guide, related to basic soldering techniques was developed by Thompson [4], and has been widely used in the Discover Mechanical Engineering pre-freshman orientation program at MIT. Using the basic tools, and drawing knowledge from this handout, the TA and their peers, the class collectively developed the initial motion control and lighting system for the vehicle.

The initial motor control box was a simple switch-based controller. The ROV's four thrusters were controlled by double-pole double-throw (DPDT) switches on a topside control box, which sent the power directly down a Cat 5e tether with eight conductors (one pair for each motor) to a junction box on the vehicle; this junction box split up the eight conductors into the four pairs. Bulgin Buccaneer 400 series IP68-rated connectors were used for all interconnections, to maximize modularity. In some cases, especially when the wires were not a single round cable, the plugs were filled with silicone sealant before closing to avoid leaks.
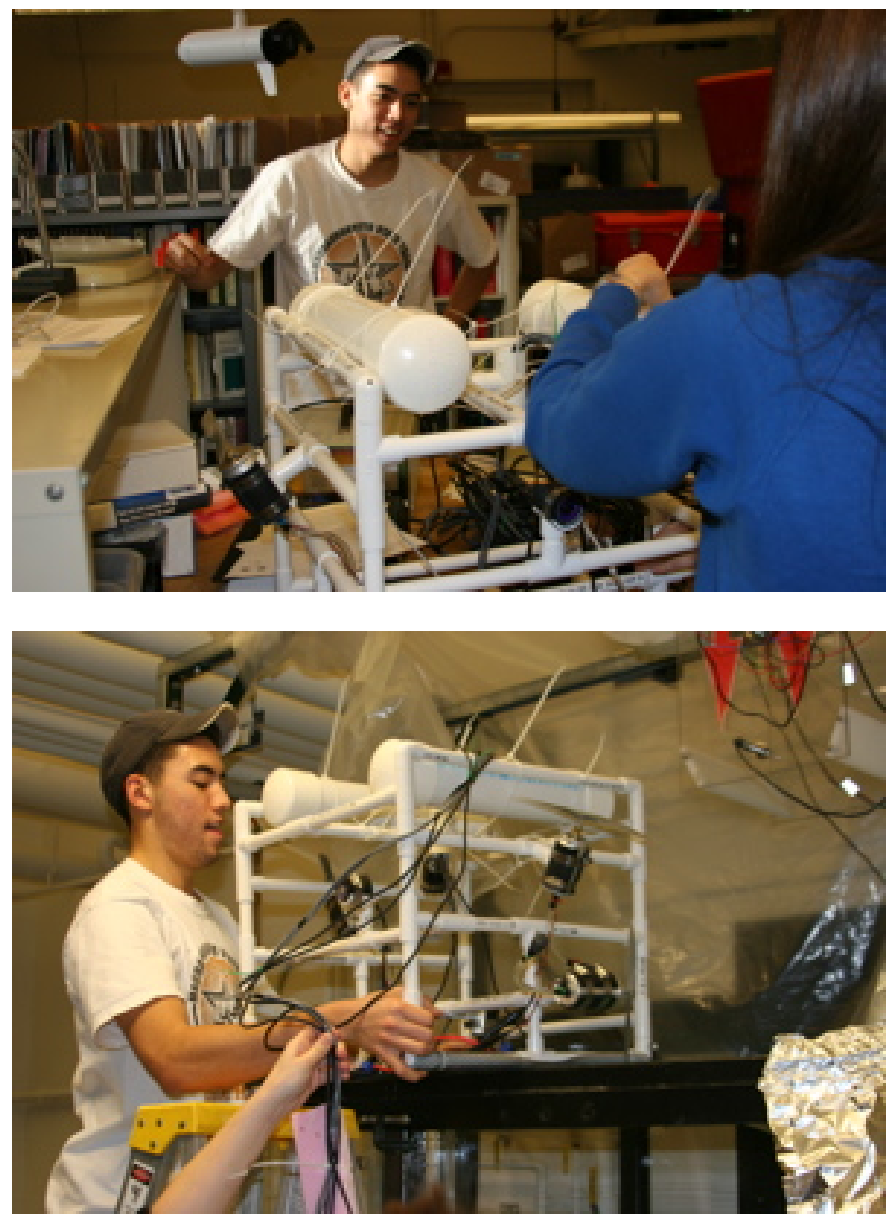

Figure 1: Students building the basic ROV frame and ballast tubes (top), first dunk test after adding the necessary ballast to maintain vehicle stability (bottom).

In constructing the basic ROV skeleton and learning these basic skills, the students had more confidence to develop their own instruments and ideas for the ROV. All of these skills are also valuable to undergraduates seeking UROP (MIT's undergraduate research opportunities program) employment and when working on senior thesis projects, and are useful beyond a degree in ocean engineering. We believe that removing the barriers associated with electronics and mechanical tools at an early stage in a student's education is crucial to opening opportunities and developing their confidence, and that this increase in confidence will improve the overall learning and subject retention of students throughout their degree program. Having only taught this class very recently we have been yet unable to test our hypothesis fully.

Parallel to these project modules, in the "lecture" portion of the class, students were learning about fundamental ocean properties (salinity, temperature, density, etc.) and basic hydrostatics (including stability so their ROV would sit vertically in the water!). The lecture on hydrostatics and stability was followed by ballasting of the vehicle and the first 
“dunk test” (figure 1, bottom). In combination with some more traditional "chalk talk" and power point lectures, as part of homework students were asked to research a topic and "teach" the class about it, typically in 5-10 minutes.

The first of these mini-presentation topics was a survey of existing underwater vehicle technologies - including ROVs, autonomous underwater vehicles (AUVs), manned submersibles, and gliders - and asked students to describe the vehicles, the missions they were designed for, the vehicles historical significance, what instruments were on board, etc. These gave students a snapshot of the current state of the art vehicles that were operating in the ocean for industry (mainly the offshore industry), government (Navy), and academic applications. At the end of the semester, during a visit to the Woods Hole Oceanographic Institution, students were also able to see a new vehicle that was under construction and represents the future of underwater vehicles. Subsequent mini-topics included oceanographic phenomenon (e.g. waves, mixing, turbulence, wind induced currents, etc.) and more advanced quantitative topics.

\section{B. Small Team Projects}

After the basic vehicle frame was built and had been tested at the MIT Towing Tank, the students went back to the white board and brainstormed again. This time they had just seen a video about hydrothermal vents in class and done some reading about basic instrumentation. They were asked to consider the challenges of operating near these vents and how researchers might go about studying the chemical and biological makeup of the fluids emanating from the vents and the surrounding environment. Ideas for instruments were written on the board in no particular order by one student as the other students called out their thoughts. In the end multiple chemical sensors, several biological sensors, and the fundamental CTD-type sensors were all listed along with video recording and velocity sensing techniques. The students often could not put a specific name to the sensor, but overall they were quite thorough in their thinking about the problem.

Following this exercise, guided by the TA and instructor, the class narrowed down the scope of instruments to be constructed and broke into groups in order to design and build their sensors. Proposals for their ideas were due around midterm and construction commenced following spring break. The instruments developed by the students included: temperature, depth, salinity, water sampling devices, vehicle velocity and heading recorders, sound recording devices, video, and computerized vehicle control system.

The finished instruments were mounted on the vehicle by each small group, however, the coordination of power and tether needs required that the small groups all interact together, especially with the motion controller and electronics groups, to ensure that the sensors could all be integrated together on the vehicle and power constraints were met.
The final vehicle can be seen in figure 2, on the dock ready for field testing. The vehicle was first tested at the MIT sailing pavilion in the Charles River and then transported for an allday field trip to the Woods Hole Oceanographic Institution (WHOI). While the weather threatened rain, winds were high, and visibility underwater was marginal, the ROV worked excellently and students caught sight of a variety of marine life and underwater debris with the underwater cameras. Due to a malfunction in the data acquisition code, data from several of the sensors was not recorded to the computer.

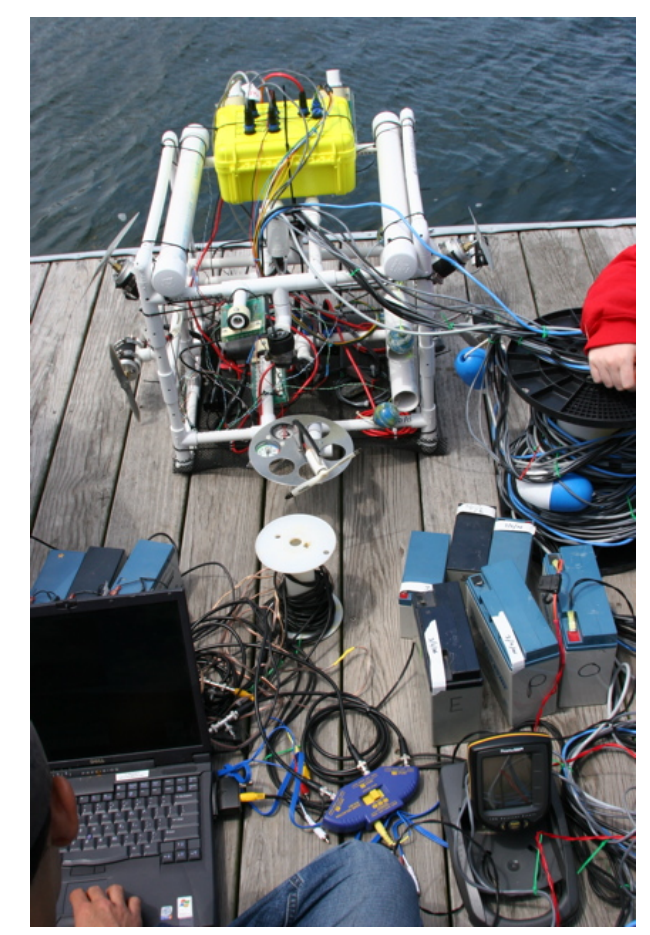

Figure 2: The final vehicle can be seen resting on WHOI's Redfield floating dock in Eel Pond during the final testing and field trip.

\section{OCEAN INSTRUMENTATION PROJECTS}

\section{A. Environmental Sensors}

Temperature, salinity and depth sensors were tackled by two small group teams. Students either found off-the-shelf instruments that they could adapt for underwater use and wire through the control system or attempted to build their own sensors. Of all the sensors chosen, salinity proved the most challenging and was ultimately scrapped due to time constraints. The students working on a depth sensor cleverly used a conventional, hand-held, fish-finder that was excellent at resolving the vehicle's depth and also mapping the "seafloor" using its built-in acoustic transducer. Classical Niskintype water samplers were developed by one of the all freshman teams. This team designed the closure mechanism and requisite electronics into a compact PVC-based bottle design which held 
almost two cups of water each. These bottles can be seen in figure 5 (top) on the starboard (right) side of the vehicle mounted on the vertical frame member.

\section{B. Vehicle control}

One ambitious group, with an electrical engineering student in it, chose to tackle the electronic control box and computer control systems (figures 3 and 4). This involved the addition of on-board processing and data logging capabilities to the ROV, allowing the sensor data to be logged on board rather than requiring cables to be run to the surface for each instrument. Thus thruster control could be handled on-board with only control signals needing to be sent from the surface over a serial connection. The modular architecture of the wiring allowed a microcontroller module to be substituted for the initial switch box built by the students, by simply swapping connectors. The microcontroller was housed in a yellow Pelican box which was sufficiently watertight for our target depths (<50 feet).

A Tattletale 8 (TT8), manufactured by Onset Computer, was used as the on-board controller with a Persister CompactFlash card for data storage, communicating over serial (RS232) with a control program running on a Windows laptop. The control program was written in Java, in order to exploit its straightforward library for the creation of graphical user interfaces (GUIs). Thruster motor control was accomplished using commercially available radio-control speed controller modules. The Time Processing Unit on the TT8 allowed the generation of the PWM signals for motor control to be independent of the main stream of execution, which periodically polls the analogue input channels to obtain sensor readings and log them to the CompactFlash card.

\section{Video and directional control}

Off-the-shelf, waterproof to $100 \mathrm{ft}$, bullet style video cameras were combined with LED light banks designed by the students to serve as the visual navigation system. Three cameras were mounted to the robot. Forward and downward looking cameras were used to visually inspect the surrounding environment, and the third camera was focused on a simple SCUBA dive compass which helped the driver roughly determine the vehicle's heading. Of these systems, the light banks required the most electronics knowledge and not having prior experience with electronic circuits, the students researched LED lights and basic circuit theory, developed the circuit diagram (figure 5, top) and constructed the light banks (figure 5, bottom). The students chose blue-green LEDs since green light tends to travel the farthest in water. A bank of LCD screens was constructed as part of the "command center" (figure 3).

\section{SEA TRIAls And Assesments}

At the conclusion of the course, the class took a field trip to the Woods Hole Oceanographic Institution (WHOI) for sea trials (figure 7). Due to the high winds and rough seas, we tested the vehicle in a sheltered pond (Eel Pond, in Woods Hole, MA). The vehicle thrusters were not designed to battle the strong currents or waves that were prevailing that afternoon, thus the protected pond was an ideal testing location. The vehicle

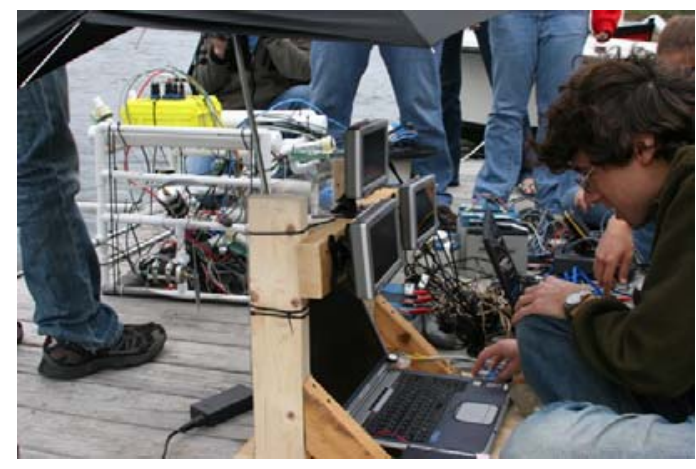

Figure 3: "Command Center" with computer control and video display console was constructed to facilitate vehicle operation.

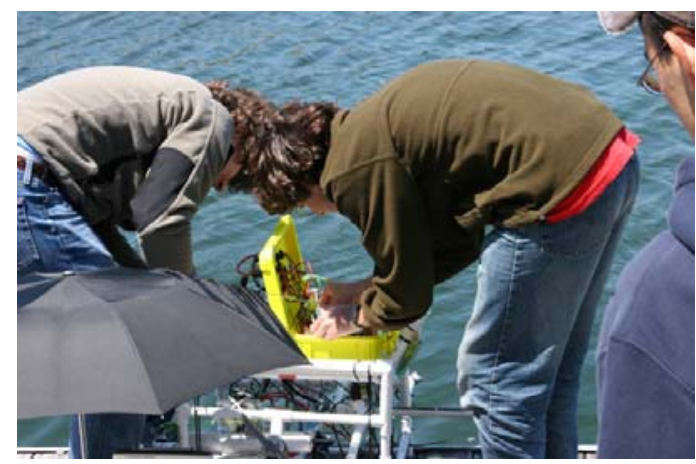

Figure 4: Last minute electronics testing inside the control box (yellow) and searching for a leak.
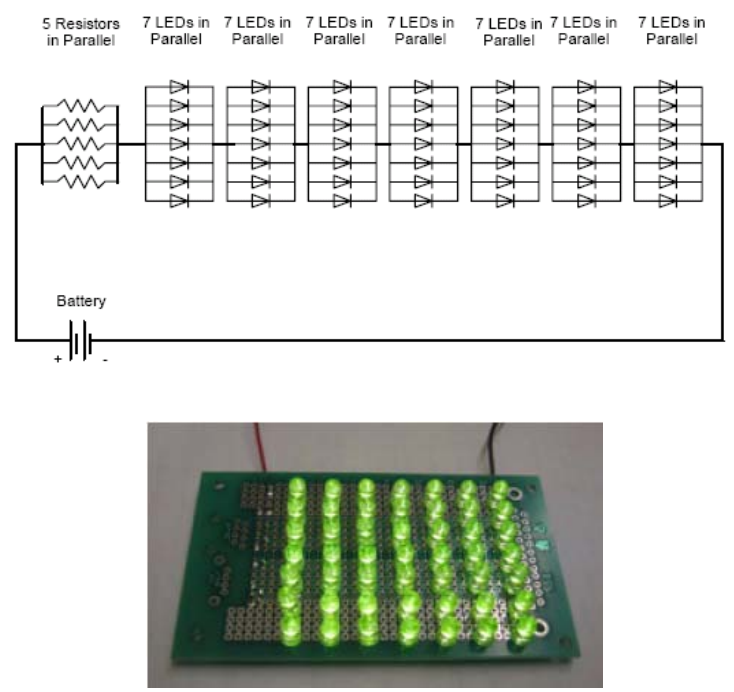

Figure 6: Light bank circuit diagram (above), working light bank of 49 blue-green LEDs (below). 
performed very well and the camera systems worked as expected. Overall the experience was a marked success.

Assessment of the course effectiveness and outcomes was performed through weekly homework assignments, two inclass exams, and a final course evaluation. In retrospect a midterm course evaluation would have be useful to us as well. The assessment of longer term objectives are ongoing and require continued assessment over time. The project portions of the class scored well in terms of overall student satisfaction and learning; the use of mini-presentations while initially awkward for many students, became more comfortable and exciting to students as the course progressed. In the future, we hope to explore using these assignments for more quantitative problem solving assignments. Course material and further information about this Introduction to Ocean Science and Engineering class (MIT subject number 2.011) are in the process of being migrated to the MIT Open Courseware Site (http://ocw.mit.edu).

\section{MEChanicAL AND OCEAN ENGINEERING}

Following the merger between the Departments of Mechanical and Ocean Engineering at MIT, in 2005, a new degree program was developed to offer students a Batchelor of Science in Mechanical and Ocean Engineering. The degree track is offered within the Department of Mechanical Engineering (Course 2) as a separate track from the traditional Mechanical Engineering degree. This degree offers students an excellent, highly technical curriculum that is designed around the core courses taught in the Mechanical engineering degree program with specialization in Ocean Engineering topics such as oceanography, hydrodynamics, acoustics, structures, and ship power and propulsion. The capstone design project is still a cornerstone of this program and continues to challenge students to think about topics of critical importance in ocean engineering today.

A comprehensive outline of this degree is online at the MIT Department of Mechanical Engineering website (http://me.mit.edu). The program is under review for accreditation by ABET in the upcoming academic year. The first student to receive this degree graduated in 2006 and is attending graduate school for an advanced degree in Ocean Engineering this fall.

\section{CONCLUSIONS}

We feel strongly that using project-based and other inductive learning techniques is highly applicable in any ocean engineering degree program. Introducing fundamental OSE topics to first and second year students, will hopefully help them to excel in their subsequent courses with the realization of "why" they topics that they are learning are important in ocean engineering. Providing an application framework early on will ideally enhance their curiosity and motivation throughout their academic track and future career. In addition we hope that this subject will help to draw students into the new degree program in Mechanical and Ocean Engineering.

\section{ACKNOWLEDGMENTS}

The authors would like to thank the Ocean Engineering Teaching Laboratory Staff, Christiaan Adams and Dr. Franz Hover for their assistance. Generous funding for development of the project modules, supplies and equipment was provided by the MIT Alumni Fund; their support is greatly appreciated.

\section{REFERENCES}

[1] T. F. Ogilvie, “Ocean Engineering in the '90's”, Marine Technolgy, 30(2), 79-83, 1993.

[2] M. J. Prince, and R. M. Felder, "Inductive teaching and learning methods: definitions, comparisons and research bases," J. Engr. Education, 95(2) 123-138, 2006.

[3] MIT SeaGrant SeaPearch: http://web.mit.edu/seagrant/edu/seaperch/

[4] M. K. Thompson, "Electronic Assembly," unpublished report.
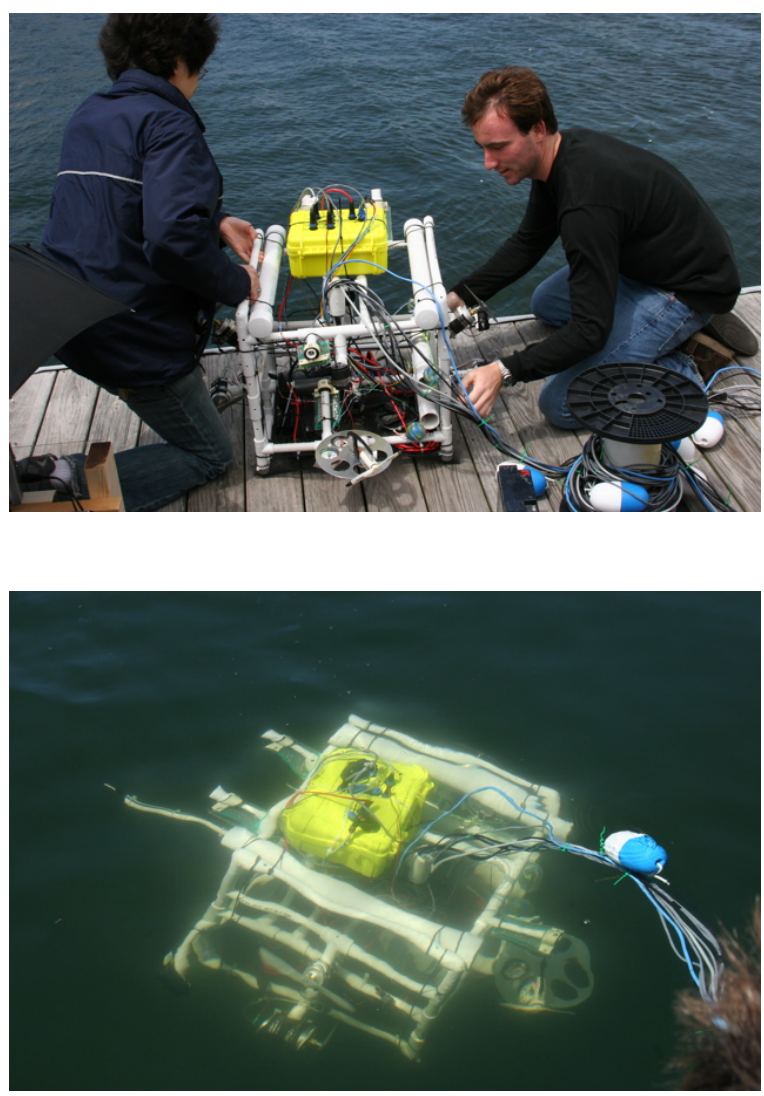

Figure 7: Prepared to launch the vehicle (top); the vehicle in action (bottom). 